\title{
Hypopharyngeal Cancer pN2a TNM Finding v8
}

National Cancer Institute

\section{Source}

National Cancer Institute. Hypopharyngeal Cancer pN2a TNM Finding v8. NCI

Thesaurus. Code C132968.

Hypopharyngeal cancer with metastasis in a single ipsilateral lymph node, $3 \mathrm{~cm}$ or smaller in greatest dimension and $\mathrm{ENE}(+)$; or a single ipsilateral lymph node larger than $3 \mathrm{~cm}$ but not larger than $6 \mathrm{~cm}$ in greatest dimension and ENE(-). (from AJCC 8th Ed.) 